\title{
LA INTELIGENCIA ARTIFICIAL EN EL PROCESO PENAL ESPAÑOL: UN ANÁLISIS DE SU ADMISIBILIDAD SOBRE LA BASE DE LOS DERECHOS FUNDAMENTALES IMPLICADOS
}

\author{
ARTIFICIAL INTELLIGENCE IN THE SPANISH CRIMINAL \\ PROCEEDINGS: AN ANALYSIS OF ITS ADMISSIBILITY ON THE \\ BASIS OF THE FUNDAMENTAL RIGHTS INVOLVED
}

IÑIGO DE Miguel BERIAIN

IKERBASQUE Research Professor

GI Derecho y Genoma Humano

Universidad del País Vasco. UPV/EHU

Miren Josune PÉrez Estrada

Prof. adjunta Derecho Procesal (acr. agregada)

Universidad del País Vasco. UPV/EHU

RESUMEN: En julio de 2016, el Tribunal Supremo de Wisconsin emitió una sentencia llamada a pasar a la historia. Por primera vez un tribunal de esa categoría utilizaba un algoritmo inteligente para graduar la sanción a un reo. Se abría así una nueva era en la que los juristas tendremos que empezar a discutir sobre los cambios que introducirá esta impactante tecnología en nuestro modo de conformar el Derecho. Este artículo pretende contribuir a esta apasionante tarea acometiendo una discusión absolutamente trascendental al respecto: la constitucionalidad o no del uso de mecanismos relacionados con la inteligencia artificial en el proceso penal. Con tal fin, haremos especial hincapié en la importancia del derecho a un 
proceso con todas las garantías, y en las implicaciones que el respeto a dicho precepto contiene para la materia que nos ocupa.

PALABRAS CLAVE: derecho a un proceso con todas las garantías, inteligencia artificial (IA), proceso penal.

ABSTRACT: In July 2016, the Wisconsin Supreme Court issued a ruling that is set to become history. For the first time a court of such importance used an intelligent algorithm to grade a defendant punishment. This opened a new era in which we, the jurists, will have to begin to discuss the changes that this impressive technology will introduce in our way of shaping the Law. This article aims to contribute to this exciting task by undertaking an absolutely transcendental discussion on a key topic: the constitutionality of the use of mechanisms related to artificial intelligence in criminal procedure. To this purpose, we will emphasize the importance of the right to due process and the implications that the respect of this provision implies for the issue at stake.

KEYWORDS: right to due process, artificial intelligency, penal procedure.

Recepción original: 27/05/2019

Aceptación original: 10/11/2019

SUMARIO: I. INTRODUCCIÓN. II. UNA CUESTIÓN PRELIMINAR: EL USO DE ALGORITMOS, ¿PRUEBA CIENTÍFICA? II.A. Los algoritmos: qué son y cómo funcionan. II. B. Concepto y naturaleza de la prueba científica. II.C. La cuestión a debate: el sentido de la inteligencia artificial como prueba científica en el proceso penal. III. LA INTELIGENCIA ARTIFICIAL EN EL PROCESO PENAL: AFECTACIÓN DEL DERECHO A UN PROCESO CON TODAS LAS GARANTÍAS. III.A. El contenido del derecho a un proceso con todas las garantías. III.B. Cómo afecta el uso de la inteligencia artificial en el proceso penal al derecho a un proceso con todas las garantías. IV. CONCLUSIONES. V. BIBLIOGRAFÍA.

\section{INTRODUCCIÓN}

El 13 de julio de 2016, el Tribunal Supremo del Estado de Wisconsin, en los Estados Unidos de América, publicó un fallo ${ }^{1}$ que tal vez llegue a considerarse histórico. Por primera vez, un tribunal de esta importancia adoptaba una postura sobre la admisibilidad del

${ }^{1}$ State v. Loomis, 881, N.W.2d 749, 7532 (Wis, 2016). 
uso de herramientas de inteligencia artificial, en este caso algoritmos de predicción del comportamiento, a la hora de adoptar sentencias en un proceso penal ${ }^{2}$. Para sorpresa -más bien indignaciónde quienes firman este documento, el susodicho tribunal avalaba ${ }^{3}$ el empleo del Correctional Offender Management Profiling for Alternative Sanctions (COMPAS), un programa matemático desarrollado por una empresa privada completamente opaco, esto es, sobre el que el procesado no tenía información alguna, como prueba suficiente para tomar decisiones sobre una pena de privación de libertad ${ }^{4}$.

El mismo hecho de que un tribunal de esta entidad haya sido capaz de avalar el funcionamiento de la inteligencia artificial para decidir sobre una cuestión esencial para un Estado democrático, la imposición de penas privativas de libertad es, cuando menos, el síntoma de una nueva era la aplicación de la justicia. Para bien o para mal, esta innovadora tecnología ha llegado ya a los tribunales y es para quedarse. De hecho, en los próximos años es más que probable que veamos cómo surge la discusión sobre la aplicación de algunos de sus mecanismos en el proceso penal. Así, por ejemplo, la inteligencia artificial podría utilizarse para determinar el género, etnia, edad, clase social, etc. ${ }^{5}$, de un probable culpable de un concreto delito -lo que, a su vez, podría emplearse como prueba indiciaria frente

${ }^{2}$ La cuestión era, incluso, sangrante si tenemos presente que, además, su capacidad de predecir la peligrosidad del reo no había sido verificada independientemente, y que su funcionamiento implicaba el manejo de datos referentes a la etnicidad, el género o el lugar de residencia del afectado. Véase, FREEMAN K., "Algorithmic Injustice: How the Wisconsin Supreme Court Failed to Protect Due Process Rights in State v. Loomis”, 18 N.C.J.L. \& Tech. On. 75, 2016.

Disponible:

http://ncjolt.org/wp-content/uploads/2016/12/Freeman_Final.pdf

3 De hecho, el Tribunal afirmaba en su sentencia: "La evaluación del COMPAS le identifica como una persona de alto riesgo para la comunidad. Sopesando los diversos factores, descarto la libertad condicional debido a la gravedad del delito y porque sus antecedentes, su historial de supervisión y las herramientas de evaluación de riesgos que se han utilizado sugieren que usted es una persona con un riesgo extremadamente alto de reincidir en el delito.". State v. Loomis, 881, N.W.2d 749, 7532 (Wis, 2016), 755.

${ }^{4}$ Veáse, al respecto, DE MIGUEL BERIAIN, I., "Does the use of risk assessments in sentences respect the right to due process? A critical analysis of the Wisconsin v. Loomis ruling", Law, Probability and Risk, Volume 17, Issue 1, 1 March 2018, págs. 45-53.

5 Esto, de hecho, ya se hace, sin ir más lejos, en los análisis de $\mathrm{ADN}$, al menos en el caso del género y la etnia. Recuérdese que, en el caso del asesinato de Eva Blanco, por ejemplo, el análisis del ADN hallado en el cuerpo de la víctima determinó que el sospechoso debería ser un varón magrebí, señalando también cuál habría de ser su color de pelo y ojos. Véase, Diario Público, 01-10-2015.

Disponible:

http://www.publico.es/actualidad/cuatro-pruebas-adn-clave-atrapar.html 
a un acusado ${ }^{6}$. También es posible, por ejemplo, que nuestro sistema judicial se plantee el uso de algoritmos de reconocimiento facial capaces de apoyar al tribunal en su percepción de si un testigo o el propio acusado levantan falso testimonio gracias a la interpretación de sus movimientos corporales, las palabras utilizadas, etc ${ }^{7}$, o que estas herramientas adquieran un peso realmente sustancial a la hora de decidir sobre la personalidad del sujeto que se somete a juicio y sus probabilidades de desarrollar o no una conducta criminal como la que se juzga, en el momento presente o en el futuro ${ }^{8}$.

A partir de esta evidencia, parece interesante comenzar ya, ahora mismo, a estudiar la posible incardinación del uso de los mecanismos de inteligencia artificial en nuestro marco jurídico penal, de modo que ésta sea tan pacífica y fructífera como resulte posible, aun siendo conscientes de que habrá una parte de la doctrina que probablemente rechazará su uso de plano ${ }^{9}$. El objetivo de este texto, por consiguiente, será analizar la cuestión planteada desde diferentes perspectivas. Así, y en primer lugar, analizaremos si este tipo de pruebas tendrían o no cabida en el proceso de acuerdo con el marco que incardina todo lo referente a la admisibilidad de la prueba en el contexto de nuestras normas procesales. Pero, elevando un poco más el listón, en la segunda parte de este texto analizaremos este problema desde la perspectiva de unos derechos fundamentales a los que no debemos ni queremos renunciar: el derecho a un proceso

${ }^{6}$ Piénsese, por ejemplo, en un caso de homicidio en el que un algoritmo determine que el culpable más probable será un varón, de etnia magrebí, y que en un pueblo en concreto sólo haya tres personas que correspondan a la descripción.

7 Así, por ejemplo, véase, Newscientist, 04-11-2015.

Disponible:

https://www.newscientist.com/article/mg22830462-700-lie-detecting-algorithmspots-fibbing-faces-better-than-humans/

Y PÉREZ-ROSAS, V. (AAVV), Deception Detection using Real-life Trial Data. Computer Science and. Engineering. University of Michigan, 2015.

Disponible:

http://dx.doi.org/10.1145/2818346.282075.

${ }^{8}$ Una enumeración detallada de los mecanismos de inteligencia artificial que se aplican en los sistemas de justicia la realiza GUZMÁN FLUJA, V. C., "Sobre la aplicación de la inteligencia artificial a la solución de conflictos (Reflexiones acerca de una transformación tan apasionante como compleja", Justicia Civil y Penal en la era global, VVAA (ed. BARONA VILAR, S.), Tirant lo Blanch, Valencia, 2017, págs. 67-122.

9 Así parecen afirmarlo, por ejemplo, las opiniones contenidas en textos como los siguientes: detractores de su utilización son, ad exemplum, PRAT WESTERLINDH, C. "Nuevos detectores de mentiras y derecho penal", La Ley penal: Revista de Derecho penal, procesal y penitenciario, 2011, pág.84; BALLESTIN MIGUEL, A., "P300: Inhumanizando la justicia", Jueces para la Democracia, Boletín Informativo, 2014, pág. 62; RICHARD GONZÁLEZ, M., Admisibilidad, eficacia y valoración de las pruebas neurológicas en el proceso penal, Iuris, enero 2014. 
con todas las garantías (que constituye el equivalente nacional al derecho al debido proceso) y el derecho -inmediatamente ligado al anterior- a no declarar contra uno mismo. No obstante, y antes de entrar en todo ello, convendrá dedicar un breve espacio a aclarar qué son y cómo funcionan estos mecanismos de inteligencia artificial, de manera que sea posible profundizar en una cuestión preliminar de esencial importancia: la de su fiabilidad científica y su carácter o no de prueba de este tipo.

\section{UNA CUESTIÓN PRELIMINAR: EL USO DE ALGORITMOS, ¿PRUEBA CIENTÍFICA?}

\section{II.A. Los algoritmos: qué son y cómo funcionan}

Entrando por tanto ahora al objetivo que nos hemos marcado procederemos a describir, aunque sea de manera sucinta, lo que ahora constituye nuestro objeto de estudio, los algoritmos inteligentes. Y quizás convenga anticipar que éstos son, precisamente, lo que parecen: series de ecuaciones matemáticas que se entrelazan para proporcionar un resultado, una instrucción concreta, que sirva para solucionar el problema planteado, gracias a la consideración de un número de variables que varía sustancialmente de un caso a otro ${ }^{10}$. El COMPAS, que hemos mencionado en el apartado precedente, emplea unas 137, de acuerdo con la información suministrada por su desarrollador ${ }^{11}$. Por hacernos una idea de la complejidad que pueden llegar a alcanzar, quizás sea oportuno mencionar que un algoritmo elaborado que ahora se está utilizando en un programa piloto en el Hospital de Stanford para calcular la probabilidad de supervi-

10 La definición básica de un algoritmo es simple: un conjunto de instrucciones paso a paso para resolver un problema o realizar una tarea. Una receta para galletas con trocitos de chocolate es un algoritmo. Obviamente, el tipo de algoritmos de los que hablaremos aquí es un poco más complejo. Acerca de qué algoritmos se están utilizando en el campo de la salud. Véase, 10 Algorithms that are changing health care, Agorithms for Innovation, 2015.

Disponible:

https://uofuhealth.utah.edu/innovation/blog/2015/10/10AlgorithmsChangingHeal thCare.php

${ }^{11}$ El COMPAS dice operar sobre la base de un análisis complejo que implica el uso de información procedente de una encuesta de 137 cuestiones separadas en varias secciones diferentes e información correspondiente a los antecedentes penales públicos individuales. 
vencia de un paciente al año de su ingreso hospitalario incluye miles de variables ${ }^{12}$.

¿Cómo se construye un algoritmo y cuál es la lógica que se esconde tras de sí? Esta es una excelente pregunta, ya que uno sólo puede comprender el reto al que nos enfrentamos si se da cuenta de cuál es la filosofía que se esconde detrás de esta nueva tecnología. La clave aquí será interiorizar una idea muy simple, pero muy contra intuitiva: un algoritmo no busca certificar la veracidad o no de una hipótesis planteada -que es lo que hace habitualmente la ciencia- sino buscar correlaciones deterministas entre unos datos y otros de manera totalmente azarosa en un principio ${ }^{13}$. Un algoritmo se construye gracias a la utilización de una gran base de datos ordenados de manera comprensible (Smart data), que un modelo matemático va utilizando de manera aleatoria, hasta establecer patrones de correlación determinista entre ellos. Gracias a esto, la herramienta consigue realizar apreciaciones muy precisas.

Esta es, precisamente, una de las claves de los algoritmos: su función, su utilidad, reside en su capacidad de anticipar comportamientos, de adivinar tendencias, de atestiguar la verosimilitud de un testimonio, aún cuando sean totalmente incapaces de explicar cómo han llegado a hacerlo. La mayor parte de construcciones generan

12 AVATI, A. et al., Improving Palliative Care with Deep Learning. arXiv:1711.06402 [cs, stat], 2017.

Disponible:

https://arxiv.org/abs/1711.06402

Para construir el modelo se utilizó una base de datos llamada STRIDE, propiedad de la Universidad de Stanford, de la que se obtuvieron datos de aproximadamente dos millones de pacientes adultos y de pediatría, atendidos en el Hospital de Stanford y el Lucile Packard Children's hospital atendidos entre 1995 y 2014. El resultado final de este esfuerzo fue la creación de una Deep Neural Network, un modelo que utiliza miles de variables para obtener sus resultados. Los test preliminares, que consistieron en la revisión de los casos de 50 pacientes elegidos al azar, demostraron que la herramienta conseguía predecir la mortalidad de manera razonablemente aceptable. En consecuencia, debería permitir mejorar el tratamiento a los pacientes con ingreso hospitalario.

${ }^{13}$ Como escribe COTINO HUESO, L., "Big data e inteligencia artificial. Una aproximación a su tratamiento jurídico desde los derechos fundamentales", Dilemata, 2017, págs. 24, 131-150, "Frente a la contrastación de una hipótesis a partir de los datos, se descubren correlaciones sin conocer previamente la causa. Así sucede al probar casi aleatoriamente la posible correlación entre datos en principio totalmente distantes ( ¿Compra distintos alimentos la gente en función del estado del clima? ¿Cómo influye el embarazo en las decisiones de consumo? ¿Sería posible ofrecer seguros de salud en función de las búsquedas en Google o del análisis de las preferencias alimentarias manifestadas por los usuarios y por sus redes de amigos en espacios sociales de internet?)" 
correlaciones, no cadenas de causalidad ${ }^{14} \mathrm{y}$, en general, son incapaces de proporcionar las claves de su propio funcionamiento, con las únicas excepciones de algunos algoritmos particularmente sofistica$\operatorname{dos}^{15}$, especialmente complejos y de muy elevado coste ${ }^{16}$. Dicho de otro modo, un algoritmo predice, pero no explica. Esto se debe, primordialmente, a que buena parte de la forma en que refinan sus predicciones y reorganizan las variables a utilizar se automatiza, de manera que incluso sus programadores encuentran dificultades para saber qué es lo que el mecanismo está haciendo exactamente y por qué lo hace ${ }^{17}$. En este sentido, esta tecnología desafía, directamente,

${ }^{14}$ Como indica GIL GONZÁLEZ, E. "Big data, privacidad y protección de datos". XIX Edición del Premio Protección de Datos Personales de Investigación de la Agencia Española de Protección de Datos, Madrid, págs. 28 y 43, "se está produciendo un cambio de la «causalidad» a la "correlación». (2016). Ya no importa tanto descubrir la causalidad entre dos hechos, sino su correlación. Así, en lugar de tratar de comprender exactamente por qué una máquina se estropea o por qué los efectos secundarios de un medicamento desaparecen, el big data permite a los investigadores recoger y analizar cantidades masivas de datos sobre estos eventos y todo lo asociado a éstos, para encontrar relaciones entre variables que permitan descubrir patrones ocultos y predecir cuándo estos eventos pueden volver a ocurrir"

Disponible:

https://www.agpd.es/portalwebAGPD/canaldocumentacion/publicaciones/common/premios_2015/Big_Data_Privacidad_y_proteccion_de_datos.pdf

15 Así, por ejemplo, "El programa Watson Paths, concretamente, permite que los médicos vean las pruebas y el sendero de deducciones que ha seguido el ordenador para lanzar sus conclusiones (por ejemplo, cómo ha concluido el diagnóstico médico que realiza). Este experimento pionero intenta dar una solución a esta falta de supervisión humana de los resultados de los algoritmos, a la falta de una traducción máquina-humano, que sin duda seguirá avanzando a medida que la ciencia del Big Data progrese. El ordenador Watson no es la única iniciativa en este sentido. Algunas empresas aseguran que sus empleados revisan las recomendaciones que hacen sus ordenadores, "aunque es raro que rechacen lo que dictan los algoritmos", GIL GONZÁLEZ, E., "Big data, privacidad y protección de datos”. XIX Edición del Premio Protección de Datos Personales de Investigación de la Agencia Española de Protección de Datos, op. cit., págs. 28 y 43.

16 DOSHI-VELEZ, F., y KORTZ MASON, K., Accountability of AI Under the Law: The Role of Explanation Berkman Center Research Publication Forthcoming, November 3, 2017.

Disponible:

http://dx.doi.org/10.2139/ssrn.3064761. Preimpreso: arXiv:1711.01134.

https://arxiv.org/pdf/1711.01134.pdf

17 Las estructuras algorítmicas de toma de decisiones contienen cientos de reglas que son muy difíciles de inspeccionar visualmente, especialmente cuando sus predicciones se combinan probabilísticamente de forma compleja. Además, los algoritmos son, a menudo, desarrollados por grandes equipos de ingenieros a lo largo de mucho tiempo, lo que hace inviable una comprensión holística de su desarrollo y sus valores y sesgos. En ambos aspectos, el procesamiento algorítmico contrasta con la toma de decisiones tradicional, donde los seres humanos responsables de la toma de decisiones pueden, en principio, articular su razonamiento cuando son consultados, limitados sólo por su deseo y capacidad de dar una explicación, 
la forma de entender la ciencia que hemos construido tradicionalmente, que se basaba en la idea de que una de las funciones del saber consistía en explicar el porqué de las cosas. Un algoritmo contradice esta creencia, dotándonos de un mecanismo útil para predecir, pero, a menudo, sólo gracias a un alto precio: una incapacidad general de transmitirnos cuál es la forma en que realiza esa predicción.

Hay, por fin, que tener presente que los algoritmos pueden encontrar relaciones entre el resultado final que se quiere medir -como la veracidad de la declaración de un testigo o de un investigado- y datos como la religión, el estatus social, la edad, el género, la etnicidad, la nacionalidad, la ocupación laboral, los datos de salud, los datos genéticos o biométricos, las creencias religiosas e ideológicas, etc., del mismo. Más aún, muchos de estos algoritmos emplean datos de este tipo incluso sin haberlos pedido nunca explícitamente, a través de la creación de datos inferidos ${ }^{18}$ de los proporcionados di-

y la capacidad del que hace la pregunta para entenderlo. La lógica de un algoritmo puede, en cambio, ser incomprensible para los humanos, un desafío que dificulta la legitimidad de las decisiones. Véase, BRENT DANIEL, M., ALLO, P., TADDEO, M., WATCHER, S., FLORIDI, L., "The ethics of algorithms: Mapping the debate", December 1, 2016.

Disponible:

https://doi.org/10.1177\%2F2053951716679679

${ }_{18}$ La capacidad de los algoritmos para inferir eficazmente datos no proporcionados, a menudo personales e incluso pertenecientes al tipo de los especialmente protegidos, a partir de otros que no tienen ese carácter resulta, de hecho, una amenaza latente para la distinción tradicional entre las diversas categorías de datos. Como señala el Considerando J de la Resolución del Parlamento Europeo, de 14 de marzo de 2017, con la aparición de los algoritmos inteligentes, "puede observarse la aparición de una difuminación entre datos personales y no personales derivada del uso de la analítica de "macrodatos", que puede generar la creación de nuevos datos personales". Más aun, parece del todo acertada su Consideración General 3, cuando señala que "puede inferirse información delicada sobre las personas de datos que no sean de carácter sensible, lo que desdibuja la línea entre la información delicada y la que no es de carácter sensible". Piénsese, en este sentido, en la dificultad de diferenciar entre datos de salud y los que no deben ser considerados como tales. El Reglamento los define en su Considerando 35 como "Entre los datos personales relativos a la salud se deben incluir todos los datos relativos al estado de salud del interesado que dan información sobre su estado de salud física o mental pasada, presente o futura. Se incluye la información sobre la persona física recogida con ocasión de su inscripción a efectos de asistencia sanitaria, o con ocasión de la prestación de tal asistencia, de conformidad con la Directiva 2011/24/UE del Parlamento Europeo y del Consejo ( 1 ); todo número, símbolo o dato asignado a una persona física que la identifique de manera unívoca a efectos sanitarios; la información obtenida de pruebas o exámenes de una parte del cuerpo o de una sustancia corporal, incluida la procedente de datos genéticos y muestras biológicas, y cualquier información relativa, a título de ejemplo, a una enfermedad, una discapacidad, el riesgo de padecer enfermedades, el historial médico, el tratamiento clínico o el estado fisiológico o biomédico del interesado, independientemente de su fuente, 
rectamente a la máquina; de manera que, aunque, a primera vista, no se aprecie su uso, en la práctica sí que se están empleando ${ }^{19}$. De este modo, el sujeto podría ver violentada su negativa a proporcionar permiso para recabar estos datos sin que existiera una evidencia palpable de la transgresión. Y, lo que es peor, pudiera ser que esto sucediese sin que ni siquiera el desarrollador del algoritmo fuera plenamente consciente de todo ello ${ }^{20}$.

\section{II.B. Concepto y naturaleza de la prueba científica}

El avance de la ciencia produce mejoras en todos los ámbitos de la vida, también en el derecho, en general, y en el derecho procesal, en particular; en este último se traducen aunque no sólo, en un avance probatorio de la prueba pericial superando así medios de prueba anticuados y que dificultan o provocan errores en la identificación del presunto autor del hecho o en la averiguación del propio hecho delictivo.

A pesar del progreso científico no existe en derecho procesal una definición unívoca del concepto de prueba científica y las definiciones que se han dado tanto por la doctrina como por la jurispruden-

por ejemplo un médico u otro profesional sanitario, un hospital, un dispositivo médico, o una prueba diagnóstica in vitro". Sin embargo, y como hemos indicado, un algoritmo puede utilizar datos que no tienen nada que ver con éstos para indicar el tratamiento más adecuado. En tal caso, ¿serían datos de salud todos los utilizados, aunque tal vez algunos de ellos (por ejemplo, el número de usos de una tarjeta de crédito) no parezcan tener nada que ver con la salud humana?

19 Ésta, sin ir más lejos, es una de las acusaciones que se hizo al COMPAS.

20 Nótese que la distinción entre dato y dato deducido es sumamente significativa en el nuevo marco normativo. Como señala la Agencia Española de Protección de Datos (AEPD), "el derecho a la portabilidad de datos (artículo 20) entendido como el derecho del afectado a obtener, en un formato estructurado, de uso común y lectura mecánica, la información que le concierna y haya facilitado a un responsable de tratamiento cuando esa información se trata por medios automatizados y sobre la base del consentimiento o para la ejecución de un contrato. En relación con este último derecho, recientemente el Grupo de Trabajo del Artículo 29 de la Directiva 95/46/CE ha adoptado directrices sobre la aplicación del derecho a la portabilidad. En este sentido, por ejemplo, el Grupo considera que el concepto de datos facilitados por el interesado incluye los datos proporcionados de manera activa por el interesado y los datos observados (datos de ubicación, búsqueda, ritmo cardiaco, etc.) pero no incluye dentro de los datos sujetos al derecho a la portabilidad a los datos inferidos o deducidos que hayan sido creados por el responsable de tratamiento a partir de los datos proporcionados por el interesado (como pueden ser los resultados algorítmicos)". (La negrita es nuestra). Agencia Española de Protección de Datos (AEPD) y Asociación Española para el Fomento de la Seguridad de la Información, ISMS Forum Spain, Código de buenas prácticas en protección de datos para proyectos Big Data, pág. 18. 
cia se muestran incompletas. A pesar de ello, no se discute y se entiende sin problemas que la prueba científica se dirige a averiguar o probar hechos que necesitan conocimientos profesionales y técnicos muy avanzados tecnológicamente ${ }^{21}$.

La doctrina tampoco se pone de acuerdo para concretar las ciencias que puede comprender la prueba científica pero lo que sí es evidente que muchos hechos criminales graves sólo se pueden descubrir o probar a través de tecnologías de nueva generación que faciliten la convicción judicial22.

$\mathrm{Ni}$ el legislador procesal ofrece un concepto de prueba pericial ni, menos aún, de prueba científica como una variedad de ésta; lo importante para el derecho procesal es cuándo procede la práctica de prueba pericial, ie., el objeto y finalidad de la prueba pericial. Así el art. 335.1 Ley de Enjuiciamiento Civil entiende que procede dicha prueba "Cuando sean necesarios conocimientos científicos, artísticos, técnicos o prácticos para valorar hechos o circunstancias relevantes en el asunto o adquirir certeza sobre ellos...". Y en idéntico sentido el art. 456 Ley de Enjuiciamiento Criminal.

Por la juris a la vista de la carencia conceptual señalada, se siguen unos determinados criterios o requisitos de fiabilidad científica para entender que una prueba tiene la categoría de científica $\mathrm{y}$, por lo tanto, "es admisible para probar científicamente un hecho en un proceso, civil o penal"23; los mismos se detallan en el epígrafe posterior ${ }^{24}$.

${ }^{21}$ Desarrolla este tema GÓMEZ COLOMER, J.L., «Los retos del proceso penal ante las nuevas pruebas que requieren tecnología avanzada: El análisis de ADN», en GÓMEZ COLOMER, J.L. (Coord.), La prueba de ADN en el proceso penal, Ed. Tirant lo Blanch, Valencia 2014, págs. 23 y ss. PÉREZ GIL, J., El conocimiento científico en el proceso civil. Ciencia y tecnología en tela de juicio, Ed. Tirant lo Blanch, Valencia 2010, pp. 42 a 47.

22 TARUFFO, M., La prueba de los hechos (trad. Ferrer Beltrán), Ed. Trotta, Madrid 2002, p. 331, mantiene que no es posible obtener ninguna definición aceptable de prueba científica.

${ }^{23}$ Expresamente GÓMEZ COLOMER, J. L., "La prueba científica, motor de cambios esenciales en el proceso penal moderno", en Garantismo frente a eficacia, justicia frente a seguridad, p. 5.

Disponible:

http://perso.unifr.ch/derechopenal/assets/files/articulos/a_20170408_01.pdf (fecha acceso: 14/11/2019).

${ }^{24}$ Se trata de los contenidos la Sentencia del Tribunal Supremo Federal de los Estados Unidos, Daubert v. Merrell Dow Pharmaceuticals, Inc. (509 U.S. 579, 113 (1993) y que la doctrina más especializada recoge, vid., por todos, DOLZ LAGO, M.J., La prueba de ADN a través de la jurisprudencia. Una visión práctica y crítica, Ed. La Ley - Wolters Kluwer, Madrid 2016, p. 41. 
Lo referente a la cuestión de la naturaleza jurídica de la prueba científica tampoco resulta ser un debate doctrinal pacifico. Si bien resultó superado la cuestión de considerar la prueba científica como documental, debido en parte a la regulación de la prueba pericial, el problema ha surgido, de nuevo, en la actualidad y a colación de la reforma operada en la LECR en 2002, en el art. 788.2, que otorga naturaleza de prueba documental a los informes emitidos por laboratorios oficiales para el caso sólo de materia de estupefacientes aunque la ley nada dice de los informes de ADN, que entonces y ante el silencio habremos de entender de naturaleza pericial ${ }^{25}$.

\section{II.C. La cuestión a debate: el sentido de la inteligencia artificial como prueba científica en el proceso penal}

Una vez expuestas las consideraciones sobre el concepto y naturaleza de la prueba científica es el momento de pasar a formularnos la pregunta trascendental que definirá su aceptación o no en el proceso: ¿puede considerarse que tales mecanismos constituyen una forma de prueba científica ${ }^{26,}$ como el análisis del ADN, o hemos, por el contrario, de considerar que nos hallamos muy lejos de poder otorgarles tal condición? A nuestro juicio, la respuesta a esta cuestión no puede ser sobre los mecanismos que nos ocupan. Cierto es, no obstante, que esta clase de dictámenes son muy difíciles de obtener en nuestro ordenamiento jurídico, que, a diferencia de otros países $^{27}$, nunca ha llegado a desarrollar un procedimiento estandarizado que permita dilucidar si una técnica en cuestión ha de con-

25 Sobre esta cuestión ETXEBERRIA GURIDI, J.F., El análisis de ADN y su aplicación al proceso penal, Ed. Comares, Granada, 2000, pp. 314 y ss. y GÓMEZ COLOMER, Juan Luis, "La prueba científica, motor de cambios esenciales en el proceso penal moderno", op. cit., pp. 7-8 y 27-28.

26 Aquí véase el concepto de prueba científica que utiliza GASCÓN ABELLÁN, M., Validez y valor de las pruebas científicas: la prueba del ADN, Universidad de Castilla-La Mancha, 2015.

Disponible:

http://www.uv.es/cefd/15/gascon.pdf.

También coincide con el concepto que utiliza nuestra jurisprudencia habitualmente. Véanse, entre otras: STS (Sección 1 $1^{\mathrm{a}}$ ) 513/2010 de 2 de junio; STS (Sección $1^{\mathrm{a}}$ ), 1069/2012 de 2 de diciembre; STS (Sección $1^{\mathrm{a}}$ ), 925/2012 de 8 de noviembre; STS (Sección $1^{\mathrm{a}}$ ), 191/2013 de 6 de marzo. STS (Sección $1^{\mathrm{a}}$ ), 128/2009 de 11 de febrero; STS (Sección $1^{\text {a) }}$ 922/2010 de 28 de octubre; STS (Sección $1^{\text {a }}$ ), 540/2014 de 1 de julio, etc.

${ }^{27}$ Así, por ejemplo, en EE. UU. se utiliza el denominado test de Daubert, que se basa en el análisis de los siguientes parámetros, a fin de considerar que una técnica novedosa reúne un mínimo consenso científico necesario para su empleo en el ámbito forense: 
siderarse o no prueba científica o bajo qué circunstancias llegaría a serlo. Es necesario verificar la fiabilidad de estos mecanismos o señalar los requisitos que deberían cumplir para hacer prueba en el proceso penal ${ }^{28}$. De ahí que lo más lógico sea que en último término quede bajo la responsabilidad del juzgador la decisión final sobre la admisibilidad, o no, de esta clase de mecanismos. Suya será la tarea de evitar que un mecanismo de dudosa fiabilidad pueda alterar su percepción de una prueba ${ }^{29}$. Pero, a modo de simple sugerencia, nos gustaría señalar que no parece tanto que la cuestión sea obligar a que un mecanismo científico tenga un grado de fiabilidad absoluto, como ocurre con la prueba del ADN, sino más bien juzgar si mejora o no la fiabilidad de otros procedimientos alternativos para

1. Si la técnica ha sido probada y verificada en condiciones de campo (reales) y no sólo a nivel de laboratorio.

2. Si la técnica en cuestión ha sido sometida a examen y publicación en el ámbito científico del que procede.

3. Cuál es la tasa de error de la técnica.

4. La existencia y mantenimiento de normas y controles en cuanto a la práctica de la técnica en cuestión 7.

5. El grado de aceptación de la técnica por parte de la comunidad científica.

${ }^{28}$ La determinación de la cientificidad de estas herramientas como prueba es un tema que deberá abordarse a medida que se generalice su uso. Sobre esta cuestión, véase, ALCOCEBA GIL, J. M., "Los estándares de cientificidad como criterio de admisibilidad de la prueba científica", Revista Brasileira de Direito Processual Penal, vol. 4, n. 1, p. 215-242, jan./abr. 2018. Disponible: https://doi.org/10.22197/rbdpp. v4i1.120 (fecha acceso: 13/11/19).

${ }^{29}$ Recordemos que los criterios de cientificidad que sirven para considerar que una prueba tiene la categoría de científica en nada tienen que ver con la admisibilidad de la prueba que se rige por el criterio de la pertinencia judicial. Ni tampoco influyen sobre la valoración de la prueba que realice el juez en virtud del principio de libre valoración de la prueba que impera en el proceso penal. Señala estas limitaciones GÓMEZ COLOMER, J. L., "La prueba científica, motor de cambios esenciales en el proceso penal moderno", op. cit., pp. 5 y 15. 
el mismo fin ${ }^{30}$, a lo que, por cierto, tradicionalmente no sometemos a escrutinios tan leoninos ${ }^{31}$.

Hay que tener siempre presente que, a diferencia de lo que ocurre en mecanismos como el de la prueba del ADN o la Onda P300 ${ }^{32}$,

${ }^{30}$ En este sentido, cabe pensar, por ejemplo, que "la detección de mentiras es una actividad compleja (...) Diversos estudios han puesto de manifiesto que el éxito en reconocer el engaño es similar al que se produce al azar (DEPAULO B. M., KASHY D. A., KIRKENDOL S. E., WYER M. M., EPSTEIN J. A. Lying in everyday life, J. Pers. Soc. Psychol, 1996.70, 979-995). Otros hallazgos, incluso, muestran que ese porcentaje del $50 \%$ se cumple tanto para personas no entrenadas como para la gran mayoría de los profesionales que se dedican al tema de la detección del engaño (DEPAULO, y otros, Cuest to Deception, Psychological Bulletin Copyright 2003 by the American Psychological Association, Inc. 2003, Vol. 129, No. 1, 74-118). Por tanto, se ha visto que la capacidad de detección del engaño por parte de los profesionales de la policía se acerca a los porcentajes del azar, aunque diversos programas de entrenamiento y la experiencia parecen contribuir a que esos porcentajes aumenten", PETISCO RODRÍGUEZ, J. M., "Las mejores tecnologías en detección de Mentiras". Actualidad Criminológica UCJC, Edición Número 2, septiembre, 2015, págs. 1-4. "Las mejores tecnologías en detección de Mentiras", Edición n ${ }^{\circ} 2$ - septiembre 2015 - Actualidad Criminológica UCJC, pág 4). Los algoritmos de los que estamos hablando parecen elevar esa capacidad de detección al 70\%. La cuestión, por tanto, sería, ¿por qué hemos de negar la plausibilidad de su empleo mientras aceptamos que un humano intervenga, cuando es claro que sus probabilidades de acertar son menores?

${ }^{31}$ Nos haremos eco aquí de VILLAMARÍN LÓPEZ, M. L., Neurociencia y detección de la verdad y del engaño en el proceso penal. El uso del escáner cerebral (fMRI) y del brainfingerprinting (P300). Marcial Pons, Madrid, 2014, cuando escribe que «lo que nos parece llamativo es el altísimo nivel de exigencia en cuanto a la fiabilidad de estas técnicas, que, en general, superan lo exigido por la comunidad científica para su reconocimiento, mientras se siguen admitiendo sin dudar medios de investigación o de prueba bastante o muy endebles que, al menos por el momento, pueden ser confrontados con estos nuevos procedimientos».

32 El test P300 puede definirse como "una técnica neurofisiológica que, a través de la electroencefalografía, mide la actividad eléctrica positiva del cerebro (P) que aparece 300 milisegundos (300) después de que un individuo haya sido expuesto a un estímulo - visual, auditivo, etc.-, de ahí su denominación como P300" SÁNCHEZ RUBIO, A., "El uso del Test P300 en el proceso penal español: algunos aspectos controvertidos". Revista Electrónica de Ciencia Penal y Criminología, 2016, $\mathrm{n}^{\circ}$ 18-04, págs. 1- 23. Disponible:

http://criminet.ugr.es/recpc/18/recpc18-04.pdf

La misma autora explica su funcionamiento así: "El mecanismo que se emplea durante la práctica de esta técnica es bastante sencillo: se utiliza un casco provisto de una serie de electrodos conectados a un amplificador, el citado casco se coloca sobre la cabeza del individuo que va a ser sometido al test y éste debe concentrarse en una pantalla donde aparecen ciertas imágenes, palabras y/o sonidos a lo largo de la duración de la prueba. Para asegurarnos de que el individuo está atento en todo momento es necesario que presione una serie de botones cada vez que aparezca un estímulo. Como resultado de tal exposición, si la persona que está siendo sometida al test reconoce una imagen o le es familiar el contenido de una pregunta, desde su cerebro se propagarán de forma prácticamente instantánea a la superficie las ondas P3008 — por ejemplo, si el sospechoso al que se le practica la prueba es quien ha co- 
cada algoritmo, cada forma de aplicación de inteligencia artificial es un mundo en sí mismo. No nos hallamos de ninguna forma ante una tecnología de una pieza, sino que puede haber cientos o miles de algoritmos diferentes encaminados a resolver un único problema, por ejemplo, si un sujeto sometido a interrogatorio miente o no. Por eso mismo, no cabe tanto hablar de aceptación generalizada de esta tecnología como de la posibilidad o no de considerar científicamente fiable a un algoritmo concreto. Pero esto supone tanto como que habrá que estar al caso concreto, esto es, que cualquier algoritmo que pretenda utilizarse en un proceso penal habrá de demostrar su fiabilidad científica, lo que difícilmente se logrará sin que se someta a procesos de validación independiente, que deberán certificar su grado de precisión.

Ahora bien, a fuerza de ser fieles a la realidad, hay que hacer notar que precisamente este extremo, esto es, el de cómo certificar la fiabilidad de un sistema de inteligencia artificial constituye ahora mismo uno de los ejes centrales del debate jurídico en torno a la cuestión, que no conoce todavía una respuesta adecuada. Piénsese en este sentido que toda validación de un algoritmo debe prestar atención tanto a la posibilidad de que éste presente sesgos que discriminen a unas personas frente a otras ${ }^{33}$, de acuerdo con los intereses o las inclinaciones de los programadores ${ }^{34}$, como a su grado de fiabilidad predictiva, lo que muchas veces dependerá de la propia calidad de los datos utilizados en su confección ${ }^{35}$. Por esto mismo, pa-

metido un homicidio y ha utilizado para perpetrarlo una escopeta, si se le muestran imágenes del arma empleada dicha onda se producirá, pero si se le expone la fotografía de una sierra mecánica dicha onda tendrá lugar con mayor amplitud" (Ibidem, 5).

${ }^{33} \mathrm{Al}$ menos más allá de lo humanamente inevitable, ya que un mínimo sesgo se hallará siempre presente.

34 Como han señalado, entre otros, BOYD Y CRAWFORD, los números no hablan por sí mismo; las afirmaciones de objetividad y precisión son engañosas dado que todos los investigadores son intérpretes de datos y siempre hay un proceso de "limpieza de datos" inherentemente subjetivo. Véase, BOYD, D. y CRAWFORD, K., Six Provocations for Big Data, Symposium on the Dynamics of the Internet and Society, (September 21, 2011): A Decade in Internet Time.

Disponible:

https://ssrn.com/abstract=1926431 o http://dx.doi.org/10.2139/ssrn.1926431

En el mismo sentido, véase, SURDEN, H., Values Embedded in Legal Artificial Intelligence. U of Colorado Law Legal Studies Research Paper, March 13, 2017.

Disponible:

https://ssrn.com/abstract=2932333 o http://dx.doi.org/10.2139/ssrn.2932333

35 Como señala el Considerando M de la Resolución del Parlamento Europeo, de 14 de marzo de 2017, "debe hacerse una distinción entre cantidad y calidad de los datos a fin de facilitar la utilización eficaz de los macrodatos (algoritmos y otras herramientas analíticas); y que los datos y/o los procedimientos de baja calidad en los 
rece evidente que, como ha señalado el Parlamento Europeo, serán necesarias "evaluaciones periódicas sobre la representatividad de los conjuntos de datos, así como examinar la exactitud e importancia de las predicciones"36. De ahí, en suma, que antes de tomar una decisión sobre la posibilidad de utilizar estos mecanismos en nuestros sistemas jurídicos sea necesario resolver previamente la cuestión de cómo regular los mecanismos que garantizarán una adecuada auditoría de su funcionamiento ${ }^{37}$, una necesidad que no es fácil de cumplimentar, por cuanto muchos de ellos, como hemos avanzado ya, son inherentemente, opacos ${ }^{38}$.

Por lo tanto, si bien no se debiera exigir que estas técnicas tengan un grado de fiabilidad absoluto, si, necesariamente, debe vigilarse

que se basan los procesos de toma de decisiones y las herramientas analíticas podrían dar lugar a algoritmos sesgados, correlaciones falsas, errores, una subestimación de las repercusiones éticas, sociales y legales, el riesgo de utilización de los datos con fines discriminatorios o fraudulentos y la marginación del papel de los seres humanos en esos procesos, lo que puede traducirse en procedimientos deficientes de toma de decisiones con repercusiones negativas en las vidas y oportunidades de los ciudadanos, en particular los grupos marginalizados, así como generar un impacto negativo en las sociedades y empresas".

${ }^{36}$ Resolución del Parlamento Europeo, de 14 de marzo de 2017, Considerando 20.

37 Algunas sugerencias particularmente lúcidas figuran en el "discussion paper" del UK ICO, que señala que "Las técnicas de auditoría pueden utilizarse para identificar los factores que influyen en una decisión algorítmica. Los sistemas de visualización interactiva pueden ayudar a los individuos a entender por qué se hizo una recomendación concreta y darles control sobre futuras recomendaciones. Los comités de ética pueden utilizarse para ayudar a dar forma y mejorar la transparencia del desarrollo de algoritmos de aprendizaje automático. Debemos, en suma, utilizar sistemas de supervisión que combinen garanticen la transparencia de los algoritmos empleando a la vez un enfoque técnico y organizativo".

UK Information Commissioner's Office (ICO), Big data, artificial intelligence, machine learning and data protection, 2017, pág. 86.

Disponible:

https://ico.org.uk/media/for-organisations/documents/2013559/big-data-ai-mland-data-protection.pdf

${ }^{38}$ Como escribe COTINO HUESO, «Big data e inteligencia artificial. Una aproximación a su tratamiento jurídico desde los derechos fundamentales» op. cit., pág. 139 “...entiendo que este tipo de garantías frente a la discriminación van a tener que combinarse con el reconocimiento de fuertes facultades de acceso y conocimiento de los algoritmos y los grandes datos que se manejan por parte de sectores especializados, tanto públicos como de la sociedad civil (reguladores, académicos, industria, asociaciones de consumidores, etc. (...)." Y dicha transparencia ha de venir acompañada asimismo con el reconocimiento de fuertes potestades de control a autoridades independientes respecto de los "data brokers" que son claves en el sector. Sin perjuicio del control social por la sociedad civil especializada, entiendo que son idóneas las autoridades independientes cercanas al sector de las nuevas tecnologías, como lo son las autoridades de protección de datos y transparencia. EU, AEPD-ISMS, 2017, Código de buenas prácticas en protección de datos para proyectos de Big Data”, op. cit. págs. 26 y ss. 
un total encaje en el sistema de protección de los derechos fundamentales y garantías procesales.

\section{LA INTELIGENCIA ARTIFICIAL EN EL PROCESO PENAL: AFECTACIÓN DEL DERECHO A UN PROCESO CON TODAS LAS GARANTÍAS}

Imaginemos que en un futuro próximo sea posible afrontar adecuadamente los problemas referentes a la fiabilidad científica que hemos constatado en el apartado anterior. ¿Sería todo ello, por sí, suficiente para asegurar la aceptabilidad de estos mecanismos? A nuestro juicio, no es tan sencillo. La validez científica sólo puede llegar a certificar que una tecnología es apta para su uso, pero la decisión final sobre si cabe utilizarla o no ha de basarse en un estudio sobre su encaje en nuestro sistema de derechos fundamentales. Y es que, sin ir más lejos, en el caso de la Onda P300 lo que parece haber determinado su rechazo no son tanto las prevenciones sobre su fiabilidad -que también parecen solventes- sino, por encima de todo, su inherente intrusión en un derecho tan fundamental como el de no declarar frente a uno mismo. La cuestión, por tanto, consiste en saber si el uso de la inteligencia artificial en el proceso penal atentaría o no contra derechos fundamentales consagrados por nuestro sistema. De ahí, por tanto, que sea ahora momento adecuado para analizar esta cuestión, lo que implicará necesariamente incorporar algunas reflexiones sobre nuestro sistema procesal y el papel que el derecho al proceso con todas las garantías juega en él.

\section{III.A. El contenido del derecho a un proceso con todas las garantías}

El proceso penal se encuentra configurado como el único sistema que permite descubrir la verdad de los hechos y determinar el sujeto responsable, siempre que se respete al principio contradictorio. El proceso penal moderno debe además ser respetuoso con los derechos humanos y con los derechos de las víctimas y hace suyas las garantías que contienen los textos internacionales en el ámbito de los derechos fundamentales de naturaleza procesal. ${ }^{39}$ Ahora bien, ¿en qué consiste exactamente el proceso con todas las garantías?

39 De las funciones del proceso penal en el Estado de Derecho da buena cuenta el autor ASENSIO MELLADO, J. M., "El proceso penal con todas las garantías", Ius et Veritas, $n^{\circ} 33,2006$, págs. 236-24, poniendo de relieve la imposibilidad en un Es- 
El derecho a un proceso con todas las garantías se encuentra ubicado, en el punto segundo del art. $24 \mathrm{CE}$, junto con otros derechos allí reconocidos: "Todos tienen derecho...a un proceso...con todas las garantías...". Su carácter autónomo del resto de derechos ha sido ya apuntado por parte de la doctrina procesal pero quizá la problemática de este reconocido derecho estriba en determinar su concreto contenido procesal, pues estamos ante un concepto jurídico indeterminado ${ }^{40}$. En lo que la doctrina coincide es que se trata de un derecho procesal predicable para todos los órdenes jurisdiccionales, no sólo aplicable al orden jurisdiccional penal ${ }^{41}$ y contemplado como principio procesal ${ }^{42}$ desligado del derecho fundamental a la tutela judicial efectiva contemplado en el art. $24.1 \mathrm{CE}^{43}$.

tado de Derecho de un proceso penal en contra de los "valores de la cultura democrática". En sus palabras, la eficacia del proceso penal radicaría en la "condena del auténtico culpable", lo contrario, la condena de un inocente convertiría al proceso en ineficaz o, incluso, en un no proceso, en un "simple expediente inquisitivo". Se trata de un proceso penal informado por los principios de contradicción e igualdad de las partes, "respetuoso con los derechos fundamentales, especialmente el de defensa - pilar del contradictorio y definidor, por excelencia, del concepto mismo de proceso" (en palabras del autor), págs. 235-236.

${ }^{40}$ Así lo pone de relieve CALDERÓN CUADRADO, M. P., "El derecho a un proceso con todas las garantías (aspectos controvertidos y jurisprudencia del Tribunal Constitucional)", Cuadernos de Derecho Público, no 10 (mayo - agosto, 2000), pág. 154. La autora mantiene que se trata de un "derecho complejo, en ocasiones incorrectamente delimitado - de ahí la confusión de ciertas sentencias del Tribunal Constitucional-...”, pág. 155.

${ }^{41}$ MONTERO AROCA, J., "Los principios políticos del poder judicial”, Derecho Jurisdiccional I, Parte General, $25^{\mathrm{a}}$ ed., VVAA, (dirs. MONTERO AROCA, J., GÓMEZ COLOMER, J. L. y BARONA VILAR, S.), Tirant lo Blanch, Valencia 2017, pág. 89 , entiende que la garantía procesal penal del derecho al juez ordinario predeterminado por la ley no se encuentra limitada, en exclusiva, al proceso penal porque “...además de procesal, es también jurisdiccional, pues atiende a la composición y funcionamiento de los tribunales, independientemente del proceso en que éstos conozcan".

${ }^{42}$ DE LA OLIVA SANTOS, A., VVAA (dirs. DÍEZ-PICAZO GIMÉNEZ, I., VEGAS TORRES, J.), Derecho Procesal. Introducción, Centro de Estudios Ramón Areces, Madrid 1999, pág. 65 lo califica de «genuino principio procesal...Porque no se trata sólo ni principalmente de una opción sobre la estructura y la configuración formal del proceso, sino de un criterio básico para decidir el derecho con las debidas garantías de acierto».

43 Ya la sentencia del Sentencia del TC 46/1982, de 12 de julio (BOE núm. 185, de 04 de agosto de 1982), ECLI:ES:TC:1982:46, establece la diferencia entre el apartado 1 del art. 24 y el 2 en el que se establecen determinadas garantías procesales: «El art. 24 de la Constitución, en sus dos epígrafes, previene dos supuestos íntimamente relacionados entre sí, pero que merecen un tratamiento diferenciado, ya que el segundo de ellos apunta preferentemente a las llamadas «garantías procesales» -así el derecho al Juez ordinario predeterminado por la Ley, asistencia letrada, información de la acusación, proceso público, utilización de los medios de prueba pertinentes y presunción de inocencia-, mientras que el primero, al proclamar el derecho a obtener la tutela efectiva de los Jueces y Tribunales en el ejercicio de los de- 
Una vez eliminados contenidos específicos propios del apartado primero del art. $24 \mathrm{CE}$ la doctrina mayoritaria y el Tribunal Constitucional coinciden en que la finalidad de este derecho radica en "salvaguardar la presencia de ciertas instituciones específicas en la ordenación y tramitación de la realidad procesal de modo que su falta en la configuración legal de la forma "en que debe realizarse el derecho objetivo por los órganos jurisdiccionales" o, incluso, "en la propia actuación de éstos" vulneraría el derecho a un proceso con todas las garantías $^{44}$. Se le otorga, por lo tanto, un trato de «cláusula de cierre» del sistema de garantías procesales, amparando derechos procesales que no están expresamente recogidos en el art. $24 \mathrm{CE}^{45}$. Incluso se ha ido más allá, al utilizar el TC el derecho a un proceso con todas las garantías para acoger garantías procesales establecidas en normas internacionales sobre derechos humanos. ${ }^{46}$

Podemos, en suma, concluir que el principio procesal del derecho a un proceso con todas las garantías o los principios-derechos que conforman el proceso penal constituyen una garantía

rechos e intereses legítimos previniendo que nunca pueda producirse indefensión, establece una garantía, previa al proceso, que lo asegura, cuando se dan las circunstancias requeridas al efecto. Dicho de otro modo, el art. 24.2 también asegura la «tutela efectiva», pero lo hace a través del correcto juego de los instrumentos procesales, mientras que el 24.1 asegura la tutela efectiva mediante el acceso mismo al proceso».

${ }^{44}$ Estas consideraciones las formula CALDERÓN CUADRADO, M. P., "El derecho a un proceso con todas las garantías (aspectos controvertidos y jurisprudencia del Tribunal Constitucional)”, Cuadernos de Derecho Público, op. cit., pág. 158.

45 De esta manera lo contempla PICÓ I JUNOY, J., "Derecho a un proceso con todas las garantías", Las garantías constitucionales del proceso, Bosch, Barcelona, 2012, pág. 159.

Disponible:

https://app.vlex.com/\#vid/382082726

Con este mismo tratamiento ESPARZA LEIBAR, I., El principio del proceso debido, Bosch, Barcelona 1995.

46 Así lo recoge la sentencia, por todas, TC 245/1991, de 16 de diciembre (BOE núm. 13, de 15 de enero de 1992), ECLI:ES:TC:1991:245 cuando declara que el derecho a un proceso con todas las garantías contiene los derechos proclamados en el art. 6.1 CEDH, F.J $2^{\circ}$ : “...en el proceso se quebrantaron reglas legales constitutivas de garantías esenciales del procedimiento, que asegura el art. 6.1 del Convenio Europeo pero que nuestra Constitución protege también como derechos fundamentales en el art. 24 C.E., en particular, en la referencia al derecho a un proceso público con todas las garantías, contenida en el art. 24.2 C.E. El derecho a un proceso con todas las garantías, al igual que los demás derechos fundamentales, ha de ser interpretado de conformidad con los Tratados y Acuerdos Internacionales sobre derechos humanos ratificados por España (art. 10.2 C.E.), entre los que ocupa un especial papel el Convenio Europeo de Derechos Humanos y Libertades Fundamentales, del que el TEDH realiza la interpretación y cuyas decisiones son obligatorias para nuestro Estado." 
fundamental de la Justicia como valor superior del ordenamiento jurídico de un Estado de Derecho ${ }^{47}$. Se trata, en definitiva, de asegurar la confianza que los tribunales han de inspirar en una sociedad democrática ${ }^{48}$.

\section{III.B. Cómo afecta el uso de la inteligencia artificial en el proceso penal al derecho a un proceso con todas las garantías}

Una vez abordado el contenido del derecho a un proceso con todas las garantías, es hora ya de afrontar la cuestión esencial sobre si el uso de algoritmos o de otras herramientas de inteligencia artificial puede o no ser admisible en nuestro marco jurídico sobre la base del respeto a este derecho fundamental.

La utilización del uso de algoritmos o de otras herramientas de inteligencia artificial en el proceso penal incide, directamente, en las garantías procesales ${ }^{49}$. Analizar de qué manera lo hace o el alcance de la afección en el derecho a un proceso con todas las garantías será clave para poder concluir si resultan admisibles en nuestro sistema judicial penal. Habrá que señalar los principios fundamentales que forman parte del contenido del derecho a un proceso con todas las garantías (o debido proceso) que pueden resultar afectados por el uso de algoritmos u otras herramientas de inteligencia artificial.

${ }^{47}$ Respecto de los principios y derechos que son necesarios para que el poder judicial sea compatible con el estado de derecho o el principio del proceso debido, ESPARZA LEIBAR, I., "El proceso debido como único modelo aceptable para la resolución de conflictos en un estado de derecho y como presupuesto para la globalización”, El derecho procesal español del siglo XX a golpe de tango: Liber Amicorum, en homenaje a Juan Montero Aroca, VVAA (coords. GÓMEZ COLOMER, J. L., BARONA VILAR, S., CALDERÓN CUADRADO, M. P., MONTERO AROCA, J.), Tirant lo Blanch, 2012, págs. 319-337.

48 DÍEZ-PICAZO GIMÉNEZ, Ignacio, «Artículo 24. Garantías procesales», Comentarios a la Constitución Española de 1978, Tomo III, VVAA (dir. ALZAGA VILLAMIL, O.), Edersa, Madrid 1996. También, LÓPEZ ORTEGA, J. J., «El derecho al juez no prevenido y el juicio de faltas», Jueces para la democracia, nº 8, 1989, pág. 47.

49 En palabras de GUZMÁN FLUJA, Vicente C., "Sobre la aplicación de la inteligencia artificial a la solución de conflictos (Reflexiones acerca de una transformación tan apasionante como compleja)", Justicia Civil y Penal en la era global, VVAA (ed. BARONA VILAR, Silvia), op. cit., págs. 67-122, que analiza la utilización de los sistemas de inteligencia artificial como medios de solución de solución de conflictos jurídicos, sostiene que "derechos y garantías son un legado que debemos ser capaces preservar...especialmente su contenido esencial, sobre todo, en cuanto encarnan el núcleo de la propia legitimidad con la que se resuelven los conflictos jurídicos". Preservando estas garantías, el autor es partidario de utilizar las capacidades de la IA para la solución de los conflictos jurídicos, pág. 121. 
Así, comprobaremos la posible afección en el principio inherente al titular de la potestad jurisdiccional: el principio de imparcialidad judicial, así como en la igualdad de las partes en el proceso, como principio general del proceso, y en el principio de contradicción materializado en el proceso en el derecho fundamental de audiencia o defensa.

La garantía de la imparcialidad judicial ha sido incluida, de manera expresa, en el contenido del derecho a un proceso con todas las garantías del art. 24.2 CE por el TC ya desde la sentencia 145/ 1988 , de 12 de julio ${ }^{50}$, en el F.J. 5, “...debe incluirse, aunque no se cite en forma expresa, el derecho a un Juez imparcial, que constituye sin duda una garantía fundamental de la Justicia en un Estado de Derecho, como lo es el nuestro, de acuerdo con el art. 1.1 de la Constitución." ${ }^{51}$ Se trata, en definitiva, a través de la imparcialidad judicial de asegurar la efectividad del derecho a un proceso con todas las garantías, pues la imparcialidad judicial, como derecho intrínseco al desarrollo de la propia función jurisdiccional, incide en la confianza que una sociedad democrática tiene respecto de sus Tribunales. Garantizar a las partes del proceso "que no concurre ninguna duda razonable sobre la existencia de prejuicios en el órgano judicial" es tarea fundamental en un Estado de Derecho ${ }^{52}$. Pues bien,

50 BOE núm. 189, de 08 de septiembre de 1988. ECLI:ES:TC: 1988:145.

${ }^{51}$ Esta inclusión de la imparcialidad judicial en el derecho al debido proceso es propiciada por el reconocimiento, en virtud del art. 10.2 $\mathrm{CEDH}$, de la garantía recogida en el art. 6.1 CEDH "Toda persona tiene derecho a que su causa sea oída equitativa, públicamente y dentro de un plazo razonable, por un tribunal independiente e imparcial". La importancia de esta asunción es la recepción de la jurisprudencia del TEDH en la interpretación del derecho a juez imparcial. Se hace eco de dicha relevancia DÍEZ-PICAZO GIMÉNEZ, Ignacio, "Artículo 24. Garantías procesales», Comentarios a la Constitución Española de 1978, Tomo III, Artículos 24 a 38 de la Constitución Española, pág. 95. Disponible: https://app.vlex.com/\#vid/331146 (Fecha acceso: 05/05/2018).

${ }_{52}$ Así, el TC, siguiendo la doctrina del TEDH, en sentencia, entre otras, 47/2011, 12 abril (BOE núm. 111, de 10 de mayo de 2011). ECLI:ES:TC: 2011:47, F. J. 9: "Despejada la concurrencia de este óbice procesal y entrando en el fondo de la vulneración aducida del derecho a la imparcialidad judicial (art. 24.2 CE), debe señalarse que es doctrina reiterada de este Tribunal que este derecho condiciona la existencia misma de la función jurisdiccional, conforme al cual, por estar en juego la confianza que los Tribunales deben inspirar en una sociedad democrática, debe garantizarse a las partes que no concurre ninguna duda razonable sobre la existencia de prejuicios o prevenciones en el órgano judicial. A esos efectos, se viene distinguiendo entre una imparcialidad subjetiva, que garantiza que el Juez no ha mantenido relaciones indebidas con las partes, en la que se integran todas las dudas que deriven de las relaciones del Juez con aquéllas, y una imparcialidad objetiva, es decir, referida al objeto del proceso, por la que se asegura que el Juez se acerca al "thema decidendi" sin haber tomado postura en relación con él. Se ha puntualizando, no obstante, que no basta con que las dudas o sospechas sobre la imparcia- 
sentado el contenido de este principio, es claro que la utilización de algoritmos judiciales en el "iter" del proceso como técnica o prueba que se aporte al proceso por la acusación influirá en la convicción personal del juez respecto del caso concreto que está obligado a valorar y lo hará en un doble sentido. Si el algoritmo no estuviese configurado de forma adecuada o presenta sesgos el resultado de su análisis afectará a la imparcialidad del juzgador en el momento de dictar la sentencia porque su convicción judicial estará condicionada al determinado sesgo que presente la herramienta de inteligencia artificial (sesgo de género, etnia, edad, clase social, etc. o incluso determinados principios y valores del autor de la herramienta e implícitos en ella). Por el contrario, si se consigue que la herramienta de inteligencia artificial que se use tenga un alto grado de fiabilidad $\mathrm{y}$, por lo tanto, sea admisible en el proceso penal, igualmente afectará a la convicción judicial; en este caso, en el momento de valoración de la prueba por la alta posibilidad de que el juez esté conforme con los resultados de la prueba y base en éstos su resolución ${ }^{53}$.

La igualdad de las partes en el proceso la incluye el TC dentro del contenido del derecho a un proceso con todas las garantías del art. $24.2 \mathrm{CE}^{54}$. Su esencia está en garantizar que las partes del proceso gocen de los mismos derechos y se enfrenten a las mismas cargas, en igualdad de condiciones, sin que existan privilegios o desigualdades que favorezcan a una de ellas. Se trata de conseguir una igualdad efectiva al dotar a las partes de las mismas posibilidades procesales en la aportación de los hechos al proceso, en las alegaciones y en la prueba a fin de lograr la efectividad del resultado que se quiere obtener. Impedir el desarrollo de este principio privándoles de los trámites procesales legalmente previstos u obstaculizando la labor de defensa de una parte en beneficio de la otra impide que se aplique

lidad del Juez surjan en la mente de la parte, sino que lo determinante y decisivo es que las razones para dudar de la imparcialidad judicial, por un lado, queden exteriorizadas y apoyadas en datos objetivos y, por otro, alcancen una consistencia tal que permita afirmar que se hallan objetiva y legítimamente justificadas (por todas, STC 60/2008, de 26 de mayo, FJ 3)."

${ }^{53}$ En este tema y sobre la prueba científica, vid. TARUFFO, M., "Conocimiento científico y estándares de prueba judicial", Boletín Mexicano de Derecho Comparado, 2005, núm. 114, pp. 1285 a 1312.

${ }^{54}$ En la sentencia, entre otras, TC 27/1985, de 26 de febrero (BOE núm. 74, de 27 de marzo de 1985). ECLI:ES:TC: 1985:27, F. J. 3. Aunque también lo contempla, en otras ocasiones, dentro del derecho a la tutela judicial efectiva o incluso vinculado al derecho de defensa. Se entiende más apropiada su ubicación dentro de los contenidos del proceso debido al tratarse de un principio general propio del proceso.

(C) UNED. Revista de Derecho UNED, núm. 25, 2019 
con éxito este principio de igualdad de las partes en el proceso ${ }^{55}$. Entendemos que la igualdad de las partes en el proceso se verá igualmente afectada cuando la utilización del algoritmo por una de las partes puede colocarla en grado de superioridad procesal frente a la otra, en este caso de la parte acusadora frente al acusado. Y ocurrirá cuando sólo una de las partes la acusación o la ejercida por el Ministerio Fiscal, en su caso, esté en condiciones para usarla. Por lo tanto, se deberá regular la posibilidad de utilización de la herramienta de inteligencia artificial por ambas partes dada la potencialidad de la misma y no únicamente por parte de la acusación.

De modo genérico, dentro del derecho a un proceso con todas las garantías, recogido en el punto 2 del art. $24 \mathrm{CE}$, aparece también constitucionalizado el principio de contradicción o derecho fundamental de audiencia o defensa. El contenido del derecho de defensa se materializa en un doble ámbito: las partes deben poder conocer todos los materiales de hecho y de derecho que puedan influir en la convicción del juez en el momento de dictar la sentencia y la facultad de poder alegar, probar y argumentar con la misma idea de incidir en la convicción judicial ${ }^{56}$. Que duda cabe que la opacidad en el contenido de los datos que presente la herramienta de inteligencia artificial que se pueda llegar a utilizar en el proceso lesionará el derecho de defensa cuando el propio desconocimiento de la estructura que contiene el algoritmo afecte al derecho de defensa del investigado o acusado. No nos referimos tanto a que no pueda ejercer el derecho de defensa pues la contradicción está garantizada formalmente sino que el problema está en comprender cómo la herramienta inteligente o el algoritmo que se ha usado ha conseguido un determinado resultado y poder así rebatirlo.

\section{CONCLUSIONES}

No se trata en este trabajo de realizar un examen exhaustivo de las consecuencias probatorias de las herramientas de inteligencia ar-

55 MONTERO AROCA, J., "Los principios políticos del poder judicial”, Derecho Jurisdiccional I, Parte General, op. cit., págs. 253-257. Y la doctrina del TC comentada, PICÓ I JUNOY, J., "Derecho a un proceso con todas las garantías", Las garantías constitucionales del proceso, op. cit., págs. 159-160.

56 «Ningún material que pueda llegar a incidir en la resolución judicial puede mantenerse en secreto para una o las dos partes, y si ello llegara a ocurrir, estaríamos claramente ante un supuesto de indefensión»; con esta claridad argumental lo pone de manifiesto el profesor AROCA MONTERO, J., «Los principios generales del proceso", Derecho Jurisdiccional I, Parte General, 26 a ed., VVAA, (dirs. MONTERO AROCA, J., GÓMEZ COLOMER, J. L. y BARONA VILAR, S.), op. cit. págs. 251 - 253. 
tificial en nuestro proceso penal pues lejos aún está su posible aplicación como prueba en el proceso (habrá antes que constatar su fiabilidad científica). Sí queremos apuntar la probabilidad de considerarla prueba científica, su posibilidad de uso en otras fases del proceso o, incluso, plantear, de modo general, posibles consecuencias en el sistema de garantías del proceso penal.

Los algoritmos como herramienta inteligente de toma de decisiones sobre la base de una serie de pautas irrumpen en el ámbito jurídico de los EEUU con motivo del dictado de la sentencia por el Tribunal Supremo del Estado de Wisconsin el 13 de julio de 2016. A partir de ese instante, los tribunales norteamericanos han ido expresando una voluntad creciente de utilizar las herramientas de inteligencia artificial para mejorar el funcionamiento de la justicia.

En nuestro entorno jurídico, no obstante, el uso de la inteligencia artificial en el proceso penal despierta sentimientos contrapuestos. De un lado, parece preciso conceder que algunas de sus aplicaciones pueden ser de gran utilidad para cubrir múltiples carencias que ahora mismo tenemos que afrontar sin las herramientas adecuadas. De otro, es necesario reconocer que su uso puede generar también vulneraciones más o menos encubiertas de derechos fundamentales, como el derecho a un proceso con las debidas garantías, que es el que nos ha ocupado mayor espacio en este documento.

Una de las bondades de los algoritmos es, precisamente, la predictibilidad del comportamiento jurídico. A su vez, uno de los grandes problemas supone el explicar cómo funcionan los algoritmos más complejos que son los que obtienen mayores resultados de acierto. La cuestión se centra en el tipo de datos que incorporan ${ }^{57}$ y el grado de autonomía que se les conceda para efectuar la predicción; ambos elementos afectarán al grado de fiabilidad de la decisión.

La incorporación al proceso penal de la inteligencia artificial mediante el uso de algoritmos predictivos del comportamiento afecta, sin duda, como hemos analizado en este trabajo, a la esencia del propio proceso, en la forma del debido proceso como concepto constitucionalizado en el art. 24.2 CE. Podemos señalar que el error en la fuente de datos debido a la utilización de datos no fiables o de baja calidad o en el propio algoritmo o, incluso, en las interpretaciones

57 Whittaker, J., (2017) mantiene “... la importancia del dato, que será el eje de toda actividad. "Data are in the heart of everything», los datos están en el corazón de todo y la innovación se produce gracias a los datos...”, "...por lo que el mundo solo podrá entenderse a partir de la comprensión del dato." 
de las conclusiones obtenidas afecta, sin lugar a dudas, a la propia convicción judicial. Del mismo modo, la igualdad de las partes en el proceso se entendería vulnerada (aunque la desigualdad pueda darse a pesar de que no exista sesgo en los datos). La lógica del algoritmo que se aplica debe ser comprensible para las partes del proceso de manera que se garantice el derecho de defensa o audiencia

Por lo tanto, cómo afecta y en qué medida en la configuración de los principios que lo conforman conviene seguir estudiándolo de manera multidisciplinar y teniendo en cuenta la evolución futura de la herramienta.

En fin, entendemos que son muchas las razones que deberían prevenirnos frente al empleo de esta clase de herramientas, a salvo de que seamos capaces de reglamentar adecuadamente su empleo, de manera que se salvaguarden los derechos fundamentales implicados. Obviamente, estas consideraciones se circunscriben al ámbito del proceso penal y, más concretamente, al de la aplicación o no de la pena. Un observador atento tendrá, probablemente, presente que algunas de nuestras observaciones poseen menor vigencia cuando hablamos de medidas de seguridad o de decisiones que afectan, por ejemplo, a medidas a adoptar sobre reos que ya cumplen condena y que determinarán su régimen de acceso a privilegios penitenciarios. $\mathrm{Y}$ es que, probablemente, este tipo de cuestiones merecen su propio comentario, en estudio separado.

\section{BIBLIOGRAFÍA}

Agencia española de Protección de Datos (AEPD) y Asociación EspaÑOLA PARA EL FoMENTo dE LA SEgURIDAD DE LA INFORMACIÓN, ISMS Forum Spain, Código de buenas prácticas en protección de datos para proyectos Big Data (2017), pág. 18.

Disponible:

http://www.agpd.es/portalwebAGPD/canaldocumentacion/publicaciones/common/Guias/2017/GuiaBig_Data_AEPD-ISMS_Forum. pdf.

Algorithms that aRe CHANGing HEALth CaRe, Agorithms for Innovation (2015).

Disponible:

http://uofuhealth.utah.edu/innovation/blog/2015/10/10Algorithms ChangingHealthCare.php. 
Alcoceba Gil, J. M., "Los estándares de cientificidad como criterio de admisibilidad de la prueba científica", Revista Brasileira de Direito Processual Penal, vol. 4, n. 1, p. 215-242, jan./abr. 2018.

Disponible:

https://doi.org/10.22197/rbdpp.v4i1.120 (fecha acceso: 13/11/19).

Asensio Mellado, J. M., "El proceso penal con todas las garantías", Ius et Veritas, 2006, págs. 33, 236-247.

Avati, A. et al., Improving Palliative Care with Deep Learning. arXiv:1711.06402 [cs, stat], 2017.

Disponible:

https://arxiv.org/abs/1711.06402.

Ballestín Miguel, A., "P300: Inhumanizando la justicia”, Jueces para la Democracia, Boletín Informativo, 2014, pág. 62.

Bellido Penadés, R.,"El derecho a la tutela judicial efectiva en la jurisprudencia constitucional", Extranjería e inmigración. Actas de las IX Jornadas de la Asociación de Letrados del Tribunal Constitucional, Centro de Estudios Políticos y Constitucionales: Tribunal Constitucional, 2004, págs. 265-312.

Boyd, D. y Crawford, K., "Six Provocations for Big Data”, Symposium on the Dynamics of the Internet and Society, (September 21, 2011): A Decade in Internet Time.

Disponible:

https://ssrn.com/abstract=1926431 o http://dx.doi.org/10.2139/ ssrn.1926431.

Calderón Cuadrado, M. P., "El derecho a un proceso con todas las garantías (aspectos controvertidos y jurisprudencia del Tribunal Constitucional)", Cuadernos de Derecho Público, 2000, págs. 10, 154, 158.

CÁmara Villar, G., "El derecho a la tutela judicial efectiva", Manual de derecho constitucional, Vol. 2, Derechos y libertades fundamentales. Deberes constitucionales y principios rectores. Instituciones y órganos constitucionales, AAVV (coord. Balaguer Callejón, F.), Tecnos, Madrid, 2016, págs. 296 - 323

Cotino Hueso, L., "Big data e inteligencia artificial. Una aproximación a su tratamiento jurídico desde los derechos fundamentales", Dilemata, 2017, págs. 24, 131-150. 
Daniel Mittelstadt, B., Allo, P., Taddeo, M., Wachter, S. y Floridi, L., "The ethics of algorithms: Mapping the debate", Big Data \& Society, 3, 2016.

Disponible:

http://doi.org/10.1177/2053951716679679.

De La Oliva Santos, A., VVAA. (dirs. DÍEZ-PICAZO GIMÉNEZ, I., VEGAS TORRES, J.), Derecho Procesal. Introducción, Centro de Estudios Ramón Areces, $3^{\mathrm{a}}$ ed., Madrid, 2016, pág. 65.

De Miguel Beriain, I., "Does the use of risk assessments in sentences respect the right to due process? A critical analysis of the Wisconsin v. Loomis ruling", Law, Probability and Risk, Volume 17, Issue 1, 1 March 2018, págs. 45-53.

Diario Público, 01-10-2015.

Disponible:

http://www.publico.es/actualidad/cuatro-pruebas-adn-clave-atrapar.html).

Díez-Picazo Giménez, I., “Artículo 24. Garantías procesales”, Comentarios a la Constitución Española de 1978, Tomo III, VVAA (dir. ALZAGA VILLAMIL, O.), Edersa, Madrid, 1996.

Díez-Picazo Giménez, I., Artículo 24. Garantías procesales. Comentarios a la Constitución Española de 1978, Tomo III, Artículos 24 a 38 de la Constitución Española, 2006, pág. 95.

Disponible:

https://app.vlex.com/\#vid/331146.

Díez-Picazo, L., Aproximación a la tutela judicial efectiva. Persona y estado en el umbral del siglo XXI, (coord. Salinas de Frías, A.), Universidad de Málaga, Facultad de Derecho, 2001, págs. 209-232.

Dolz LAGo, M.J., La prueba de ADN a través de la jurisprudencia. Una visión práctica y crítica, Ed. La Ley - Wolters Kluwer, Madrid 2016, pág. 41.

Doshi-Velez, F., y Kortz Mason, K., Accountability of AI Under the Law: The Role of Explanation (November 3, 2017). Berkman Center Research Publication Forthcoming.

Disponible:

http://dx.doi.org/10.2139/ssrn.3064761. Preimpreso: arXiv:1711.01134. 
https://arxiv.org/pdf/1711.01134.pdf.

EsPaRza LeIBAR, I., El principio del proceso debido, Bosch, 1995, Barcelona.

- "El proceso debido como único modelo aceptable para la resolución de conflictos en un estado de derecho y como presupuesto para la globalización", El derecho procesal español del siglo XX a golpe de tango: Liber Amicorum, en homenaje a MONTERO AROCA, J. VVAA (coords. GÓMEZ COLOMER, J. L., BARONA VILAR, S., CALDERÓN CUADRADO, M. P., MONTERO AROCA, J.), Tirant lo Blanch, 2012, págs. 319-337.

- "El derecho a la tutela judicial efectiva y a un juez imparcial o el proceso debido como garantía de los derechos de los ciudadanos y de la viabilidad de la Unión Europea", La Carta de los Derechos Fundamentales de la Unión Europea y su reflejo en el ordenamiento jurídico español, Thomson Reuters-Aranzadi, 2014, págs. 831-844.

EtXeBerRia Guridi, J. F., "El derecho a la tutela judicial efectiva y a un proceso debido", La declaración Universal de Derechos: ayer, hoy y mañana, VVAA (dir. ORDEÑANA GEZURAGA, I), Thomson Reuters-Aranzadi, 2012, págs. 201-222.

ETXEBERRIA GURIDI, J.F., El análisis de ADN y su aplicación al proceso penal, Ed. Comares, Granada, 2000, pág. 314 y ss.

Figueruelo Burrieza, A., El derecho a la tutela judicial efectiva, Tecnos, 1990, Madrid.

- "Tutela judicial efectiva y sistema constitucional de fuentes del derecho", Los derechos fundamentales y libertades públicas (II) / XIII Jornadas de Estudio, Dirección General del Servicio Jurídico del Estado, Ministerio de Justicia, Centro de Publicaciones, Madrid, 1993, págs. 115-126.

Freeman K., Algorithmic Injustice: How the Wisconsin Supreme Court Failed to Protect Due Process Rights in State v. Loomis, 18 N.C.J.L. \& Tech. On. 75, 2016.

Disponible:

http://ncjolt.org/wp-content/uploads/2016/12/Freeman_Final.pdf.

GARBERí Llobregat, J., El derecho a la tutela judicial efectiva en la jurisprudencia del Tribunal Constitucional, Bosch, Barcelona, 2008.

Gascón ABEllán, M., Validez y valor de las pruebas científicas: la prueba del ADN, Universidad de Castilla- La Mancha, 2015. 
Disponible:

http://www.uv.es/cefd/15/gascon.pdf.

GIL GonZÁLEZ, E., "Big data, privacidad y protección de datos”. XIX Edición del Premio Protección de Datos Personales de Investigación de la Agencia Española de Protección de Datos, Madrid, 2016, págs. 28 y 43.

Disponible:

https://www.agpd.es/portalwebAGPD/canaldocumentacion/publicaciones/common/premios_2015/Big_Data_Privacidad_y_proteccion_de_datos.pdf.

Gómez Colomer, J. L., "La reforma estructural del proceso penal y la elección del modelo a seguir", ANUARIO DE DERECHO PENAL. Posición institucional de los sujetos en el proceso penal de menores reformado (juez, fiscal, defensor/acusado, víctima), Université de Fribourg - Département de droit pénal, 2008, pág. 5.

Disponible:

http://hdl.handle.net/10234/19633.

Gómez Colomer, J.l., Los retos del proceso penal ante las nuevas pruebas que requieren tecnología avanzada: El análisis de ADN, en GÓMEZ COLOMER, J.L. (Coord.), "La prueba de ADN en el proceso penal”, Ed. Tirant lo Blanch, Valencia 2014, pág. 23.

Gómez Colomer, J. L., "La prueba científica, motor de cambios esenciales en el proceso penal moderno", en Garantismo frente a eficacia, justicia frente a seguridad, p. 5.

Disponible: http://perso.unifr.ch/derechopenal/assets/files/ articulos/a_20170408_01.pdf (fecha acceso: 14/11/2019).

GuZmán Fluja, V. C., "Sobre la aplicación de la inteligencia artificial a la solución de conflictos (Reflexiones acerca de una transformación tan apasionante como compleja”, Justicia Civil y Penal en la era global, VVAA (ed. BARONA VILAR, S.), Tirant lo Blanch, Valencia, 2017, págs. 67-122.

Jiménez de PARga y CABRERA, M., "La tutela judicial efectiva: luces y sombras", Consolidación de derechos y garantías: los grandes retos de los derechos humanos en el siglo XXI: seminario conmemorativo del 50 aniversario de la declaración Universal de los Derechos Humanos, CGPJ, 1999, págs. 317-338. 
LÓPez ORTEGA, J. J., "El derecho al juez no prevenido y el juicio de faltas”, Jueces para la democracia, 8,1989, pág. 47.

Montero Aroca, J., "El principio acusatorio. Un intento de aclaración conceptual", Justicia: revista de derecho procesal, 4, 1992, págs. 775-788.

— "El juez que instruye no juzga", La Ley: revista jurídica española de doctrina, jurisprudencia y bibliografía, 1, 1999, págs.18011816.

- "El principio acusatorio entendido como slogan político", Ius et Veritas, 33, págs., 2006, 208-219.

- "Los principios políticos del poder judicial", Derecho Jurisdiccional I, Parte General, 25 a ed. (VVAA, MONTERO AROCA, J., GÓMEZ COLOMER, J. L. Y BARONA VILAR, S.), Tirant lo Blanch, Valencia, 2017, págs. 89, 213-219, 251-257.

Newscientist, 04-10-2015.

Disponible:

https://www.newscientist.com/article/mg22830462-700-lie-detecting-algorithm-spots-fibbing-faces-better-than-humans/

Ortells Ramos, M. y Bellido Penadés, R., "El derecho fundamental a la tutela judicial efectiva", Introducción al Derecho Procesal. VVAA (coord. ORTELLS RAMOS, M.), Thomson Reuters-Aranzadi, $7^{\mathrm{a}}$ ed., 2017, págs. 249 - 272.

Pérez GIL, J., El conocimiento científico en el proceso civil. Ciencia y tecnología en tela de juicio, Ed. Tirant lo Blanch, Valencia 2010, págs. 42 a 47.

PÉREZ-Rosas, V., (VVAA), "Deception Detection using Real-life Trial Data”. Computer Science and. Engineering. University of Michigan, 2015.

Disponible:

http://dx.doi.org/10.1145/2818346.282075.

Petisco Rodríguez, J. M., "Las mejores tecnologías en detección de Mentiras”. Actualidad Criminológica UCJC, Edición Número 2, septiembre, 2015, págs. 1-4.

Picó I Junoy, J., Derecho a un proceso con todas las garantías. Las garantías constitucionales del proceso, Bosch, Barcelona, 2012, págs.159-160. 
Disponible:

https://app.vlex.com/\#vid/382082726.

Prat Westerlindh, C., Nuevos detectores de mentiras y derecho penal, La Ley penal: Revista de Derecho penal, procesal y penitenciario, 2011, pág. 84.

Resolución del Parlamento Europeo, de 14 de marzo de 2017, Considerando 20.

Richard González, M., Admisibilidad, eficacia y valoración de las pruebas neurológicas en el proceso penal, Iuris, enero 2014.

SÁnchez RuBio, A., "El uso del test P300 en el proceso penal español: algunos aspectos controvertidos". Revista Electrónica de Ciencia Penal y Criminología, 18, 2016, págs. 1- 23.

Disponible:

http://criminet.ugr.es/recpc/18/recpc18-04.pdf

SuRdEN, H., "Values Embedded in Legal Artificial Intelligence". U of Colorado Law Legal Studies Research Paper (March 13, 2017).

Disponible:

https://ssrn.com/abstract=2932333 o http://dx.doi.org/10.2139/ ssrn.2932333

TARuffo, M., La prueba de los hechos (trad. Ferrer Beltrán), Ed. Trotta, Madrid 2002, p. 331.

TARUfFo, M., "Conocimiento científico y estándares de prueba judicial", Boletín Mexicano de Derecho Comparado, 2005, núm. 114, pp. 1285 a 1312.

UK INFORMATION COMMISSIONER's OfFICE (ICO), Big data, artificial intelligence, machine learning and data protection, 2017, pág. 86.

Disponible:

https://ico.org.uk/media/for-organisations/documents/2013559/bigdata-ai-ml-and-data-protection.pdf)

VALLESPín Pérez, D., El modelo constitucional de juicio justo en el ámbito del proceso civil: conexión entre el derecho a la tutela judicial efectiva y el derecho a un proceso con todas las garantías, Atelier, Barcelona, 2002. 
Villamarín LóPez, M. L., Neurociencia y detección de la verdad y del engaño en el proceso penal. El uso del escáner cerebral (fMRI) y del brainfingerprinting (P300). Marcial Pons, Madrid, 2014.

WhITTAKeR, J., Congreso Robotiuris 2017: crónica de un análisis multidisciplinar de la robótica y la inteligencia artificial.

Disponible:

https://www.fidefundacion.es/Video-resumen-y-cronica-de-robotiuris17_a666.html

10 Algorithms that are changing Health CaRe, Agorithms for Innovation, 2015.

Disponible:

https://uofuhealth.utah.edu/innovation/blog/2015/10/10Algorithms ChangingHealthCare.php 


\section{Acknowledgements:}

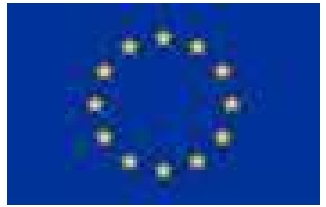

This project has received funding from the European Union's Horizon 2020 research and innovation programme under grant agreement No 788039

De Miguel Beriain, Iñigo; Pérez Estrada, Miren Josune. La inteligencia artificial en el proceso penal español: un análisis de su admisibilidad sobre la base de los derechos fundamentales implicados. Revista De Derecho UNED, NúM. 25, 2019 - pp531-561 